\title{
Bicycling to School During the Transition From Childhood Into Adolescence: A Six-Year Longitudinal Study
}

\author{
Greet M. Cardon, Lea R.D. Maes, Leen L. Haerens, \\ and Ilse M.M. De Bourdeaudhuij \\ Ghent University
}

\begin{abstract}
Little is known about bicycling to school as children age. At baseline (2002) selfreport data from 1070 children were gathered (51.9\% boys; mean age: 10 years). The measurements were repeated in 2003 ( $n=1039), 2004(n=907), 2005(n=$ $549)$ and $2008(n=515)$. The rates of children bicycling to school significantly varied across time points from $46 \%$ at the age of ten, $69 \%$ at the age of $11,83 \%$ at the age of $12,70 \%$ at the age of 13 toward $78 \%$ at the age of 16 . Starting from the age of 11, the average duration of time spent bicycling to school significantly increased over time. According to multilevel regression analyses $13.6 \%$ of the variance in rates of bicycling to school was situated at the school level, $39.6 \%$ at the pupil level and $46.7 \%$ at the measurement level. The differences in rates and durations across time points were independent from gender, BMI, SES and having siblings. Pupils engaging in bicycling to school at younger ages had a higher change of engaging in bicycling to school at 16 years old (ORs: 2.69-7.61; ICC bicycling rates: 0.46 , ICC bicycling durations: 0.82 ). This finding emphasizes the need for promoting bicycling to school at young age.
\end{abstract}

The transition from childhood into adolescence is characterized by a decrease in physical activity levels $(21,28)$. At the age of $10-12$ years children start to get more decision-making power about how they spend their leisure time and the transition into adolescence is found to be a critical period for drop out from sports clubs and increase of computer use $(32,33)$. However while total physical activity levels are found to decline from childhood into adolescence, the CLAN study showed an increase in actively commuted trips (walking and cycling) to school in Australian 12 and 14 year olds, over a 2-year period, possibly related to the gain of independence and being allowed to actively commute unchaperoned (13).

Cardon and Haerens are with the Dept. of Movement and Sports Sciences, Ghent University, Ghent, Belgium. Maes and De Bourdeaudhuij are with the Dept. of Public Health, Ghent University, Ghent, Belgium. 
Active commuting to school is a very important, yet often overlooked, source of physical activity. While sports and play activities often involve sporadic and intermittent movement, active commuting to school is a potential source of continuous moderate activity, that can take place on a daily base. Moreover the results of recent reviews show that children, who actively commute to school, are more active and fit than those who travel by motorized transport $(6,8,14)$. Cooper et al. showed in a Danish study that children and adolescents who cycled to school were nearly five times more likely to be in the top quartile of cardio respiratory fitness than those who traveled by motorized transport (5). Despite the potential health benefits, the numbers of children actively commuting, are limited and decreasing. In Australia, between 1985 and 2001, the proportion of children bicycling to school has been reduced by half (24) and similar trends are seen in the United States (16,27), Canada (2) and in the United Kingdom (7).

While secular trends are extensively studied, little is known about active commuting patterns as children age, and more specifically during the transition from childhood into adolescence. A good understanding of this transition is crucial for the development of appropriate interventions to promote active commuting. In the literature only one longitudinal study could be located, evaluating active commuting to school during this transition. The CLAN study showed that 12 year olds and 14 year olds increased their active commuting by an average of 1 and 0.6 trips/week, respectively, over 2 years (13). Limitations of the study included the small sample sizes and short follow-up time. Moreover, findings related to active commuting in Australia, may not be transferable to European children. In the same line U.S. data are not transferable to European youth since in general, active commuting to school is much less prevalent in the U.S. compared with European countries (26). Consequently a study on active commuting with a longer follow-up executed in European children is of interest.

As outlined in the literature walking and bicycling should be examined separately, as they might have different impact on health $(1,13,25)$. Moreover in some European countries bicycling to school is more common than walking to school $(12,26)$. Therefore the current study focuses on bicycling to school as a way of active commuting and data on walking to school were considered to be beyond the scope of the current study. In the current study the term "bicycling to school" is used as a generic term to reflect both bicycling to and from school.

While the literature indicates that bicycling to school becomes a more common behavior with increasing age, up to now it is unclear if bicycling to school tracks from childhood into adolescence. Furthermore, while some studies showed that active commuting is more common in boys, compared with girls $(16,26)$, only one study could be located looking into possible gender differences of this behavior during the transition from childhood into adolescence (13). In the CLAN study changes in active commuting over 2 years were similar among boys and girls (13).

To conclude, little is known about what happens to bicycling to school as children get older. Therefore the current study aims at describing the rates and durations of bicycling to school over a six year period during the transition from childhood into adolescence and to explore if gender, SES, BMI or having siblings are related to bicycling to school during this transition. Furthermore we evaluated if bicycling to school at younger age tracks into bicycling to school at age 16 . 


\section{Methods}

\section{Procedure}

The present study was executed in Flanders, the Dutch speaking part of Belgium, in the center of Europe. Data from the Longitudinal Eating and Activity study were used. The detailed methodology and data on the relationship of physical activity and dietary habits with BMI have been reported elsewhere (10). A longitudinal design was used in which children were included in the study in 5th grade of primary school and were questioned five times (T1-T5). All children of the 5th grade (10 year olds) in 59 schools were invited to participate in the study $(n=1957)$. In 2002 (T1) the children completed a self-administered questionnaire in the classroom on eating habits, physical activity and demographic variables. Questionnaires of 1670 children were gathered of which 1070 contained all information needed for the analyses in the current study. At T1 parents filled out a questionnaire on demographics and reported child length and weight. One year later, in 2003 (T2), the procedure was repeated in the same children. In total 1557 valid questionnaires were gathered of which 1039 contained all needed information. In 2004 all children left primary school and entered different secondary schools making classroom based administration of questionnaires impossible. In 2004 children were asked in a letter to their home addresses to complete a web-based questionnaire online (T3). In total 1151 questionnaires were received in this wave of which 907 containing all needed information. In 2005 (T4) and 2008 (T5) the same procedure was repeated. Respectively a total of 807 (549 contained all information) and 798 children completed the questionnaire (515 contained all information). The study was approved by the Ghent University Hospital review board.

\section{Participants}

The sample at $\mathrm{T} 1$ consisted of $51.9 \%$ boys, mean age was 10 years $(9.93, S D 0.4)$, mean BMI was 16.5 (SD 2.5) and 98\% had a Belgian nationality. Drop-out analyses were executed to look at baseline differences between those that stayed in the study over the six years compared with those that dropped out. No differences were found for gender, nationality, sports involvement, hours of physical education, and active transport. The children that dropped out were somewhat older $(p=.003)$, had a somewhat higher BMI $(p=.001)$, and were less likely to have parent(s) with a higher education $(p=.01)$.

\section{Measures}

Questions were derived from the validated Flemish Physical Activity Questionnaire $(22,31)$.

According to the study of Philippaerts et al. intraclass coefficients to verify test- retest reliability generally exceeded 0.70 (22). Bicycling to school was assessed by asking how the respondents "usually" commute to and from school in a typical week. Children bicycling to school were then asked how many minutes per day they cycled during the roundtrip to and from school. To assess sports involvement, respondents reported if they were involved in any kind of sports or not, excluding mandatory school physical education. 
Parental reports (T1) were used to calculate BMI (at age 10), for having siblings (yes/no) and for parental education levels. Parental education was used as a proxy for SES. When the highest level of education of mother or father included higher education the child was labeled as high SES, when none of the parents followed higher education, the child was labeled as low SES.

\section{Statistical Analyses}

Changes in rates of bicycling to school and duration of cycling to school across and between five time points were investigated. Given the nested structure of the data, and the adequate sample size for conducting multilevel analyses (15), multilevel regression analyses were employed using MLWiN version 2.20 (23). Although data on bicycling to school were not available for all time points for all students, the occurrence of missing data does not constitute a problem for multilevel models analyses since the software automatically takes missing data into account. As for the rates of bicycling to school 4080 measures nested in 1264 pupils nested in 59 schools were available. Of these 1264 pupils, 1070 were measured at time 1, 1039 at time 2, 907 at time 3, 549 at time 4 and 515 at time 5. As for the duration of bicycling to school only pupils bicycling to school were included resulting in 2322 measures of 879 pupils out of 59 schools.

The data were treated as a three level hierarchical model (measurement/ student/school).

Multilevel logistic regressions using a binominal respons model with a logit link function were applied for the binary data (bicycling or not bicycling to school). The Marginal Quasi-Likelihood (MQL) computed up to the 1st order was used to achieve approximation. A two step procedure was applied with iterative generalized least squares (IGLS) optimization methods followed by Bayesian approaches (MCMC sampling). The logistic transformation $g(\beta)=e^{\beta} /\left(1+e^{\beta}\right)$ was used to estimate the rates for cycling to school. Odds ratios (OR) were calculated by the

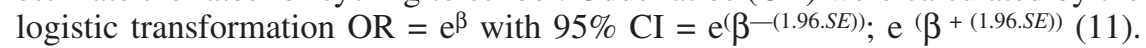
Multilevel linear regression analyses were applied for the continuous outcome of duration of bicycling to school. A baseline variance components model (23) or intercept-only model (11) was used to evaluate how much of the variation in the included outcome variables could be attributed to each of these levels. This baseline variance components model partitions the total variance of the examined variable into the between-school (Level 3), between student (Level 2) and between-time (Level 1) variance. Intraclass correlation coefficients were calculated by percentage of variation situated at each level. In a multilevel logistic regression model, the variance at the first level is set to a scale factor of 1.00; the variance of a logistic distribution with scale factor 1 is $\pi^{2} / 3=3.29$ (11). Hence, for the logistic regression analyses, measurement variance was set at 3.29.The null models further served as a baseline model with which to compare subsequent more complex models in the second step (i.e., explanatory aim) of our analyses.

The first set of analyses involved the stepwise insertion of explanatory variables. In a first step gender, SES, baseline BMI and having siblings were included to assess whether these factors were related to pupils' bicycling to school. In a second step "time" was entered as a continuous variable to assess whether pupils' bicycling to school significantly increased or decreased across time points. In a 
third step, interaction effects between the explanatory factors of model 1 (gender, SES, baseline BMI and having siblings) and time were tested, to assess whether these factors influenced changes in bicycling to school over time. Since parsimonious models are preferred, interaction terms that did not ameliorate the test model were not presented in the tables. In a final step, time was included as a categorical variable to investigate differences in bicycling to school (rates; duration) between different time points. Post hoc analyses were conducted by changing the reference category to obtain coefficients for differences between all time points.

Finally, in a second set of analyses, a two level (pupils within schools) hierarchical logistic regression analyses were conducted to investigate the odds ratio's of engaging in bicycling to school at the age of 16, for pupils engaging versus not engaging in bicycling to school at younger ages. Here again, the Marginal QuasiLikelihood (MQL) computed up to the 1st order was used to achieve approximation; and the two step procedure with iterative generalized least squares (IGLS) optimization methods followed by Bayesian approaches (MCMC sampling) was applied. Data of 515 students out of 56 schools were available at the age of 16 . Stability over time of bicycling rates and durations was calculated through the intraclass correlation coefficient derived from the random part of the variance components model. Alpha levels of $p \leq .05$ were considered as significant.

\section{Results}

\section{Rates of Bicycling to School}

Bicycling percentages according to age are presented in Figure 1. Table 1 presents the fixed and random part of the hierarchical model for the binary response of bicycling or not bicycling to schools. First, in the fixed part of the baseline variance components model (Model 0$)$, the intercept of $0.68($ S.E. $=0.13)$ refers to the logistic transformation of the odds of students engaging in bicycling to school across all time points, students and schools. By using the formula $\mathrm{g}(\beta)=\mathrm{e} \beta /(1+\mathrm{e} \beta)$, we calculated that across all measurement points $66 \%$ of the students engages in bicycling to school. The random part of the variance components model revealed that the variance was significant at the school $\left(\sigma^{2}=0.96, S E=0.26, \chi^{2}(1)=14.10\right.$, $P<0.001)$ and pupil level $\left(\sigma^{2}=2.79, S E=0.35, \chi^{2}(1)=63.56, P<0.001\right)$. Starting from the value of 3.29 as the variance of a logistic distribution with scale factor 1 , it was calculated that $13.6 \%$ of the variance in rates of bicycling to school was situated at the school level $(\mathrm{ICC}=(0.96 / 0.96+2.79+3.29), 39.6 \%$ of the variance was situated at the pupil level and $46.7 \%$ was situated at the measurement level. In a second step (See Table 1, Model 1), we investigated whether the odds of engaging in bicycling to school differed as a function of gender, SES, baseline BMI and having siblings by entering these explanatory variables in a second model. None of these predictors significantly related to engagement in bicycling to school (See Table 1, Model 1, all $\chi^{2}(1)<0.23, n s$ ). In a third step time was entered as a continuous variable in the model (Table 1, Model 2), to investigate whether the odds for engaging in bicycling to school significantly differed across time points. The results indicated a significant positive relationship between time and rates of bicycling to school $\left(\beta=0.33, S E=0.03, \chi^{2}(1)=91.18, P<0.001\right)$, indicating that children on average have $1.39\left(\mathrm{e}^{0.33}\right)$ more change of bicycling to school with 
each year that they grow older $(\mathrm{OR}=1.39 ; 95 \% \mathrm{CI}, 1.30 ; 1.46)$. Next, interaction effects between the explanatory factors of model 1 (gender, SES, BMI and having siblings) were tested. None of the interaction effects were significant (all $\chi^{2}(1)<$ $3.67, n s)$. In a final step, time was entered as a categorical variable to investigate if the odds for bicycling to school changed across different ages (or measurement points). To obtain coefficients for differences between all time points the reference category was changed in each of the models (See Table 1, Model 3a-3d). The rates of children engaging in bicycling to school to school significantly varied across time points from $49 \%$ at the age of ten, $69 \%$ at the age of $11,83 \%$ at the age of $12,70 \%$ at the age of 13 toward $78 \%$ at the age of 16 . The regression coefficients in Table 1 show that the odds of children bicycling to school changed significant with age. When compared with the age of 10 , children were more likely to cycle at the age of $11\left(\mathrm{OR}=2.34,95 \% \mathrm{CI}, 1.85 ; 2.96, \chi^{2}(1)=49.53, p<0.001\right)$, at the age of $12\left(\mathrm{OR}=5.10,95 \% \mathrm{CI}, 3.87 ; 6.72, \chi^{2}(1)=140.11, P<0.001\right)$, at the age of $13\left(\mathrm{OR}=2.44,95 \% \mathrm{CI}, 1.85 ; 3.20, \chi^{2}(1)=38.68, P<0.001\right)$ and the age of $\left.16(\mathrm{OR}=3.71,95 \% \mathrm{CI}, 2.02 ; 6.81), \chi^{2}(1)=67.74, P<0.001\right)$. When compared the age of 11 , children were more likely to cycle at the age of $12(\mathrm{OR}=2.20$, $\left.95 \% \mathrm{CI}, 1.71 ; 2.84, \chi^{2}(1)=37.22, P<0.001\right)$ and at the age $16(\mathrm{OR}=1.60,95 \%$ CI, $\left.1.19 ; 2.15, \chi^{2}(1)=10.11, P<0.001\right)$, no differences with the age of 13 were found $\left(\mathrm{OR}=1.04,95 \% \mathrm{CI}, 0.78 ; 1.40, \chi^{2}(1)=0.06, n s\right)$. When compared with the age of 12 , children were less likely to cycle at the age of $13(\mathrm{OR}=0.48,95 \%$ CI, $\left.0.34 ; 0.65, \chi^{2}(1)=21.45, P<0.001\right)$ and at the age of $16(\mathrm{OR}=0.73,95 \% \mathrm{CI}$, $\left.0.54 ; 0.99, \chi^{2}(1)=4.03, P \leq 0.05\right)$. When compared with the age of 13 , children were more likely to cycle at the age of $16\left(\mathrm{OR}=1.58,95 \% \mathrm{CI}, 1.11 ; 2.25, \chi^{2}(1)\right.$ $=6.65, P \leq 0.01$ ).

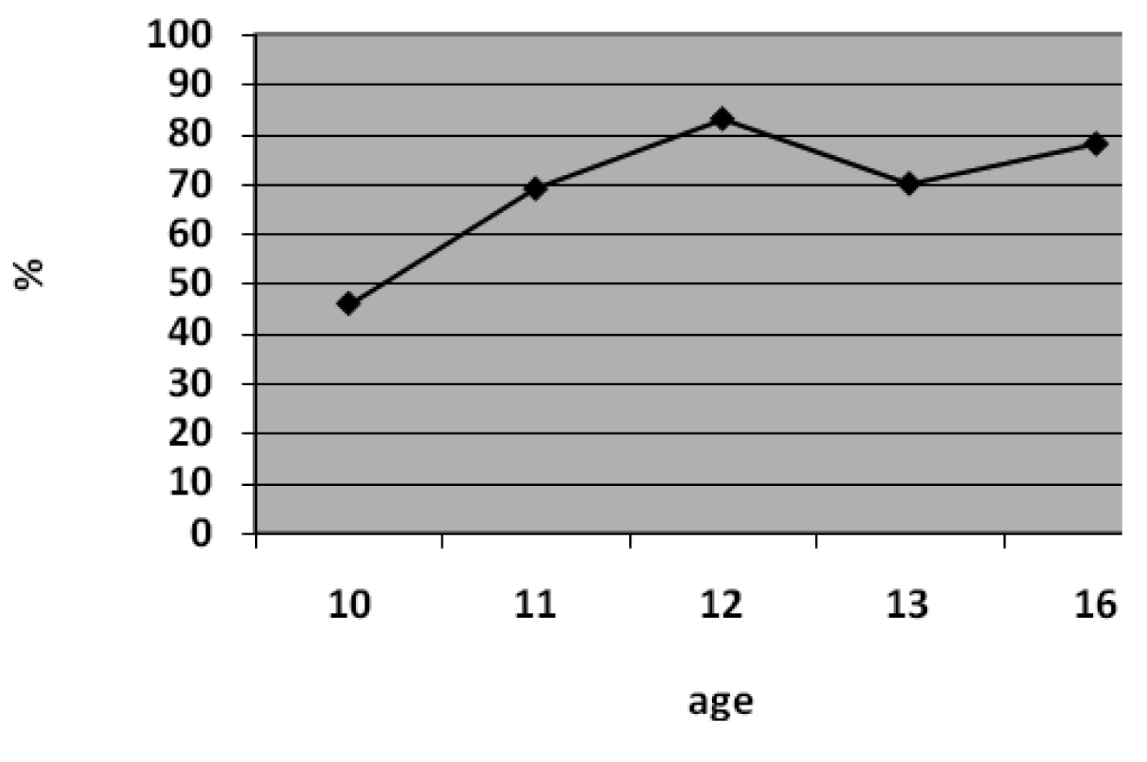

Figure 1 - Bicycling percentages according to age. 


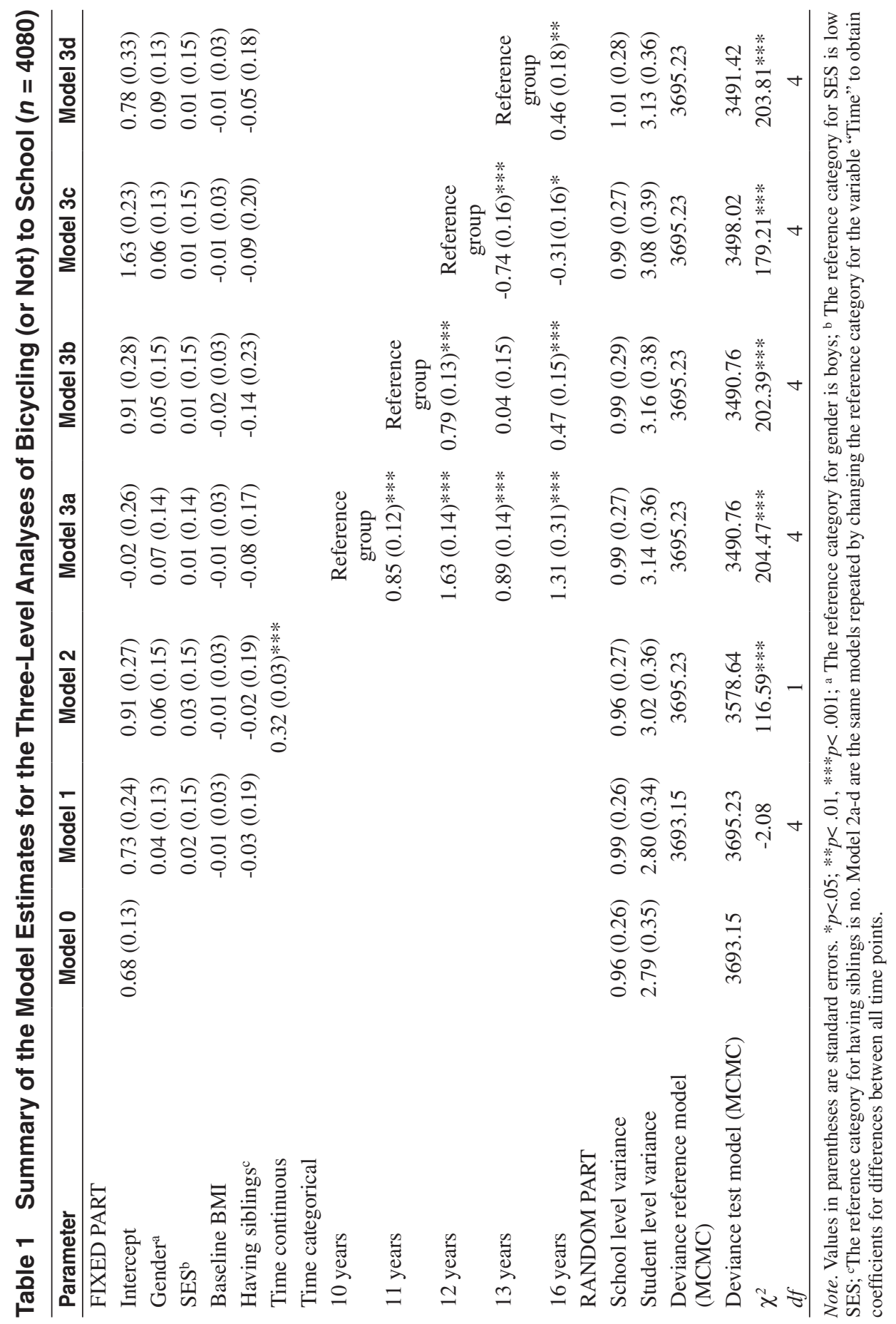




\section{Duration of Bicycling to School}

Table 2 presents the fixed and random part of the hierarchical model for the duration of bicycling to school. First, in the fixed part of the baseline variance components model (Model 0), the intercept of $14.50($ S.E. $=0.55)$ refers to the overall mean of minutes of bicycling to school across all time points, students and schools. The random part of the variance components model revealed that the variance was significant at the school $\left(\sigma^{2}=10.14, S E=3.10, \chi^{2}(1)=10.72, p<0.001\right)$, pupil $\left(\sigma^{2}\right.$ $\left.=23.16, S E=4.37, \chi^{2}(1)=28.15, P<0.001\right)$ and measurement $\left(\sigma^{2}=151.99, S E\right.$ $\left.=5.48, \chi^{2}(1)=769.81, P<0.001\right)$ level with $5.5 \%$ of the variance in bicycling to school explained at the school level, $12.5 \%$ of the variance explained at the student level and $82.0 \%$ explained at the measurement level. The latter findings indicate that two randomly chosen measures of two pupils of the same school are expected to have a correlation of 0.13 , whereas measurements of the same pupil are expected to have a correlation of 0.82 .

In a second step (See Table 2, Model 1), we investigated whether time spent in bicycling to school differed as a function of gender, SES, baseline BMI and having siblings by entering these explanatory variables in a second model. None of these predictors significantly related to time spent in bicycling to school (See Table X, Model 1 , all $\left.\chi^{2}(1)<1.43, n s\right)$. In a third step time was entered as a continuous variable in the model (Table 2, Model 2), to investigate whether time spent in bicycling to school significantly changed across time points. The results indicated a significant positive relationship between time and bicycling to school $(\beta=1.81$, $\left.S E=0.20, \chi^{2}(1)=84.17, P<0.001\right)$, indicating that across all measurement points, time spent in bicycling to school significantly increases over time. Next, interaction effects between the explanatory factors of model 1 (gender, SES, BMI and having siblings) were tested. None of the interaction effects were significant (all $\left.\chi^{2}(1)<1.05, n s\right)$. In a final step, time was entered as a categorical variable to investigate fluctuations across time points. The reference category was changed to obtain coefficients for differences between all time points (Model 3a-3d). The duration of bicycling to school significant differed across time points: $15.67(0.68)$ min at age 10, $9.24(0.70) \mathrm{min}$ at age $11,11.56(0.63) \mathrm{min}$ at age $12,18.39(0.80)$ $\mathrm{min}$ at age $13,21.82(0.78) \mathrm{min}$ at age 16 . Significantly lower durations are noticed from the age of 10 toward the age of $11\left(\beta=-6.42, S E=0.76, \chi^{2}(1)=71.62, P\right.$ $<0.001$ ), between the age of 11 and 12 years old the duration of bicycling to school is significantly higher $\left(\beta=2.31, S E=0.71, \chi^{2}(1)=10.70, P<0.001\right)$, similarly a significantly higher duration was notified from the age of 12 toward the age of 13 $\left(\beta=6.81, S E=0.82, \chi^{2}(1)=69.07, P<0.001\right)$ and from the age of 13 toward the age of $16\left(\beta=3.46, S E=0.93, \chi^{2}(1)=13.88, P<0.001\right)$.

Prediction of Bicycling to School at Age 16 by Bicycling to School at Younger Ages and Stability Over Time. Odds ratio's for bicycling to school at a younger age and bicycling to school at age 16 can be found in Table 3. Overall, pupils bicycling to school at younger ages had a higher change of bicycling to school at 16 years old $\left(\chi^{2}(1)\right.$ ranging between 6.68 at age 11 and 60.76 at age 13.)

Both for the rates of active transportation to school $(\mathrm{ICC}=0.46)$, as for the duration of bicycling to school $\left(\sigma^{2}=151.99, S E=5.48, \chi^{2}(1)=769.81, P<0.001\right.$, $\mathrm{ICC}=0.82$ ) to school, a significant variance at the measurement (time) level was notified. The ICC of 0.82 indicates that $82.0 \%$ of the variance in duration of 


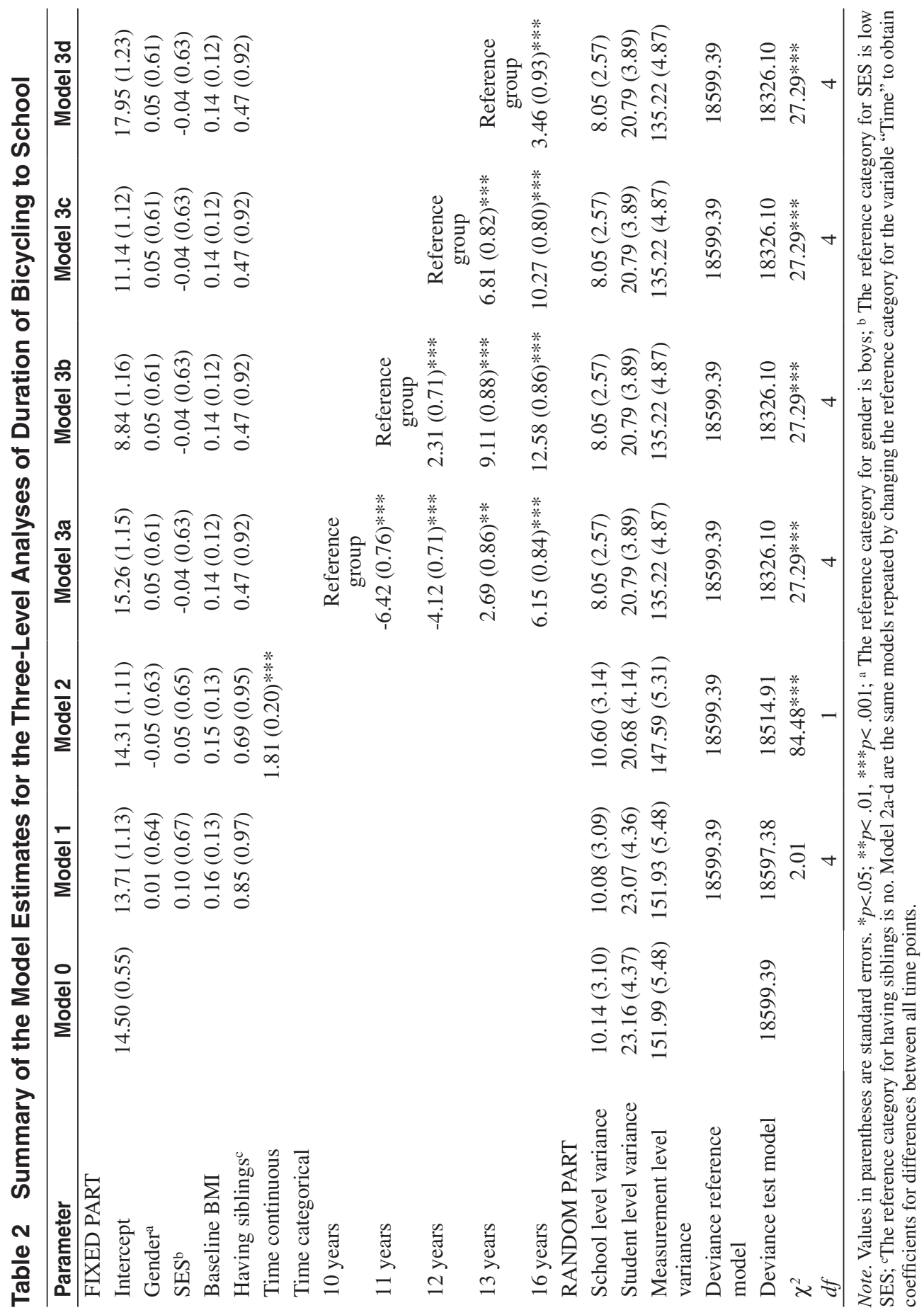




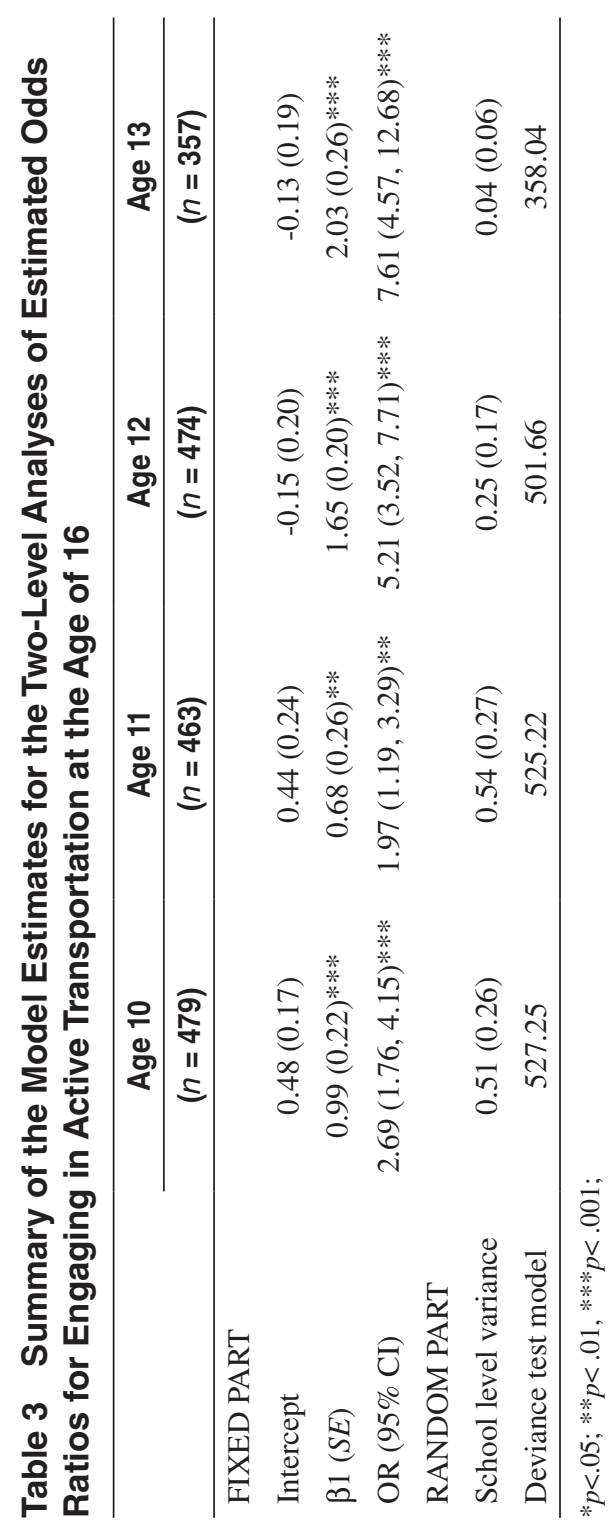


bicycling to school is explained at the measurement level. Otherwise said, two randomly chosen measures of the same pupil are expected to have a correlation of 0.82 , which suggests high stability over time in the duration spent in bicycling to school.

\section{Discussion}

The findings of the current study showed that bicycling to school is very prominent in schoolchildren in Flanders and, as expected, in general the percentages of children reporting bicycling as usual mode of travel to school considerably increased with age. At age ten $46 \%$ of the children bicycled to school, while at age 16 this percentage increased to $78 \%$. The general increase of rates might be attributable to age-related increases in independence and autonomy. Carver et al. found that fewer parents of older children report concerns about strangers and traffic than do parents of younger children (3). Consequently, as also outlined by Panter et al., efforts to facilitate independence, by the creation of a safe and supporting environment for bicycling to school and by changing parental perceptions, may be important (20). In the current study the school level explained $13,6 \%$ of the variance in bicycling rates. The incline in bicycling rates could therefore also reflect differences in school policies or other aspects of the schools (e.g., more bike stands, better access to bike lanes getting in and out of school). Consequently it can be concluded that the school plays an important role to promote bicycling to school.

The strongest increase in bicycling rates was found between the ages of 10 and 11 , just before the transition to secondary school. This may be explained by the fact that parents want to get their children to be prepared to bicycle to the secondary school, which is often located further away, as also shown in the bicycling duration rates. The general age related incline of bicycling to school is in line with the literature (13) and contrasts the decline of total activity levels, found from childhood into adolescence $(21,28)$. Consequently bicycling to school can be an important source of activity to counteract the common activity decline in this age group.

Rates of bicycling to school in Flanders are in line with percentages from Denmark, which has a comparable landscape, climate and bike lane network. In Denmark $38 \%$ of the 9 year olds and $66 \%$ of the 15 year olds cycle to school (5). On the other hand the current study showed much higher bicycling rates compared with the US, where only $0.8 \%$ of the 5-18 year olds cycles to school (16), compared with the UK, where $9 \%$ of the 9-10 year olds cycles to school (20), or compared with Switzerland, where $17 \%$ of the 6-14 year olds cycles to school (9). The high rates in Flanders might be explained by the biker-friendly environment and relatively safe environment. Flanders (surface: $13.522 \mathrm{~km}^{2}$ ) has a mild sea climate and it is characterized by a flat landscape and a dense network of street bike lanes (12.000 kilometres bike lanes). Moreover due to the high population density, the distances to schools are relatively short, which is found to strongly relate to active school transport $(16,26)$. Consequently bicycling is very prominent in Flanders, often considered as an example of a cycle-friendly region. Moreover schools in Flanders are obliged by the government to promote active travel to school, next to the promotion of e.g., healthy food and the prevention of drug abuse.

In the current study bicycling rates and durations did not differ between boys and girls. As girls of this age group are less involved in sports compared with boys $(21,28,33)$, the promotion of active transport to school seems a promising way 
to activate girls. The fact that the durations of bicycling to school did not differ according to gender, can be explained by the fact that all schools in Flanders are coeducational and thus school distances do not differ among genders. This finding also showed that girls, who bicycle to school, are prepared to cycle the same distance as boys.

In the current study no significant differences could be found for the rates of bicycling to school between low and high SES youngsters. This is in contrast with findings in the literature, showing that active commuting is more common in low SES children $(4,19)$. A possible explanation may be that bicycling is very prominent in Flanders and is not perceived as a behavior that is only needed for families that cannot afford a car.

Siblings may act as social agents, facilitating bicycling to school $(17,30)$. However in the current study having siblings did not relate to rates of bicycling to school. Possibly, the facilitating role of siblings, like chaperoning each other, may depend on the age of the siblings, which was not investigated in this study. Furthermore the present findings showed that the changes in rates and durations of bicycling to school did not differ according to pupils' baseline BMI, which might open possibilities to use bicycling to school as a way to increase physical activity in overweight children. However, a previous study in the same sample found no association between active school transportation and changes in BMI z-score over a four year period and outlined the importance of frequent sports participation and dietary behaviors to combat overweight (10).

At the age of ten $46 \%$ of the pupils are already bicycling to school. These pupils spent on average $15 \mathrm{~min}$ per day bicycling to school. From the age of 11 more pupils start to bicycle to school, but for shorter periods of time. Possibly parents of pupils living closer to school prefer their children to walk to school until their somewhat older. From the age of 13 the number of pupils' bicycling to secondary school increases and also the duration of bicycling to school is higher in older children. The average durations of bicycling to school significantly increased from 8 min for those bicycling at age 10-21 min for those bicycling at age 16. These higher bicycling durations in older children were expected since most children change schools between primary and secondary education. In Flanders the schools for secondary education are larger and smaller in number, which associates with a longer commute. Furthermore, children living somewhat further from the school, who were not bicycling to school at a younger age, may get parental allowance or may choose to cycle to school as they get older. Bicycling to school included on average about 20 min of daily activity at ages 13 and 16 . Consequently programs that promote bicycling to school may have a strong effect on youngsters' accumulated physical activity (8).

Another important finding of the current study is the fact that bicycling to school at age 10 already strongly tracks into bicycling to school at age 16 . It was found that $72 \%$ of the children bicycling to school at age 10 were still bicycling to school at age 16. Children bicycling to school at age 10 had almost four times more chance to bicycle to school at age 16. As expected, this tracking strength increased with age. About $85 \%$ of the 13 year olds bicycling to school, were still bicycling to school at age 16. Apparently, when bicycling to school is the usual transport mode in the first year of secondary school, this persists at an older age. These findings reflect the stable nature of this behavior and highlight the importance of implementing programs that promote active commuting early in life. 
A limitation of the current study is the fact that conclusions were based on self-reported measures. However a questionnaire validated in the same age group was used and the report of school transportation is expected to be reliable because it occurs regularly. Also in the literature self-reports of active commuting to school were found to be reliable $(1,18,29)$. Another limitation of the current study is the considerable drop-out. While the drop-outs between the five measurement points were limited, the drop-out from baseline to six years later is considerable. However drop-out analyses revealed only minimal differences between those that stayed in the study compared with those that dropped out.

A major strength of the current study is the fact that it advances previous research by using multiple waves of data in a relatively large sample. Moreover clustering of students within schools was taken into account by using multilevel analyses.

To further inform the development of interventions to promote active transport in children and youngsters, future studies should be undertaken in different countries to look into a broader range of potential environmental and psycho-social predictors of active transport, as children age.

\section{Acknowledgments}

This paper has been facilitated by a research grant from Ghent University (nr 01110504).

\section{References}

1. Bere, E., and L.A. Bjorkelund. Test-retest reliability of a new self reported comprehensive questionnaire measuring frequencies of different modes of adolescent commuting to school and their parents commuting to work - the ATN questionnaire. Int. J. Behav. Nutr. Phys. Act. 6:68, 2009. PubMed doi:10.1186/1479-5868-6-68

2. Buliung, R.N., R. Mitra, and G. Faulkner. Active school transportation in the Greater Toronto Area, Canada: an exploration of trends in space and time (1986-2006). Prev. Med. 48:507-512, 2009. PubMed doi:10.1016/j.ypmed.2009.03.001

3. Carver, A., A.F. Timperio, and D.A. Crawford. Neighborhood Road Environments and Physical Activity Among Youth: The CLAN Study. J. Urban Health. 85:532-544, 2008. PubMed doi:10.1007/s11524-008-9284-9

4. Chillón, P., F.B. Ortega, J.R. Ruiz, et al. Socio-economic factors and active commuting to school in urban Spanish adolescents: the AVENA study. Eur. J. Public Health. 19:470-476, 2009. PubMed doi:10.1093/eurpub/ckp048

5. Cooper, A.R., N. Wedderkopp, H. Wang, L.B. Andersen, K. Froberg, and A.S. Page. Active travel to school and cardiovascular fitness in Danish children and adolescents. Med. Sci. Sports Exerc. 38:1724-1731, 2006. PubMed doi:10.1249/01. mss.0000229570.02037.1d

6. Davison, K.K., J.L. Werder, and C.T. Lawson. Children's active commuting to school: current knowledge and future directions. Prev. Chronic Dis. 5:A100, 2008. PubMed

7. Department of Transport. National Transport Statistics Factsheet: Travel to school. London: Department of transport, 2010

8. Faulkner, G., R. Buliung, F. Parminder, and C. Fusco. Active school transport, physical activity levels and body weight of children and youth: a systematic review. Prev. Med. 48:3-8, 2009. PubMed doi:10.1016/j.ypmed.2008.10.017

9. Grize, L., B. Bringolf-Isler, E. Martin, and C. Braun-Fahrlander. Trend in active transportation to school among Swiss school children and its associated factors: three cross-sectional surveys 1994, 2000 and 2005. Int. J. Behav. Nutr. Phys. Act. 7:28, 2010. PubMed doi:10.1186/1479-5868-7-28 
10. Haerens, L., C. Vereecken, L. Maes, and I. De Bourdeaudhuij. Relationship of physical activity and dietary habits with BMI in the transition from childhood to adolescence: a 4 year longitudinal study. Public Health Nutr., in press.

11. Hox, J.J. Multilevel analysis: Techniques and applications. Mahwah, NJ: Erlbaum, 2010.

12. Hubert, J.P., and P. Toint. La mobilité quotidienne des Belges (Daily mobility of the Belgian population). Facultés universitaires Notre-Dame de la Paix. Namur, Belgique: Presses Universitaires de Namur, 2002.

13. Hume, C., A. Timperio, J. Salmon, A. Carver, B. Giles-Corti, and D. Crawford. Walking and bicycling to school: predictors of increases among children and adolescents. Am. J. Prev. Med. 36:195-200, 2009. PubMed doi:10.1016/j.amepre.2008.10.011

14. Lee, M.C., M.R. Orenstein, and M.J. Richardson. Systematic review of active commuting to school and childrens physical activity and weight. J Phys Act Health. 5:930-949, 2008. PubMed

15. Maas C.J.M., J.J. Hox. Sufficient Sample Sizes for Multilevel Modeling 2005 Methodology. 1(3):86-92, 2005

16. McDonald, N.C. Active transportation to school: trends among U.S. schoolchildren, 1969-2001. Am. J. Prev. Med. 32:509-516, 2007. PubMed doi:10.1016/j. amepre.2007.02.022

17. McMillan, T.E. The relative influence of urban form on a child's travel mode to school. Trans. Res. Part A. 41:69-79, 2007.

18. Mendoza, J.A., K. Watson, T. Baranowski, T.A. Nicklas, D.K. Uscanga, and M.J. Hanfling. Validity of instruments to assess students' travel and pedestrian safety. Public Health. 10:257, 2010. PubMed

19. Mota, J., H. Gomes, M. Almeida, J.C. Ribeiro, J. Carvalho, and M.P. Santos. Active versus passive transportation to school: Differences in screen time, socio-economic position and perceived environmental characteristics in adolescent girls. Ann. Hum. Biol. 34:273-282, 2007. PubMed doi:10.1080/03014460701308615

20. Panter, J.R., A.P. Jones, E.M.F. van Sluijs, and S.J. Griffin. Attitudes, social support and environmental perceptions as predictors of active commuting behaviour in school children. J. Epidemiol. Community Health. 64:41-48, 2010. PubMed doi:10.1136/ jech.2009.086918

21. Pate, R.R., P.S. Freedson, J.F. Sallis, et al. Compliance with physical activity guidelines: prevalence in a population of children and youth. Ann. Epidemiol. 12:303-308, 2002. PubMed doi:10.1016/S1047-2797(01)00263-0

22. Philippaerts, R.M., L. Matton, K. Wijndaele, A.L. Balduck, I. De Bourdeaudhuij, and J. Lefevre. Validity of a physical activity computer questionnaire in 12- to 18 year old boys and girls. Int. J. Sports Med. 27:131-136, 2006. PubMed doi:10.1055/s-2005-837619

23. Rasbash J., F. Steele, W.J. Browne., and H. Goldstein. A User's Guide to MLwiN, v2.10. Centre for Multilevel Modelling, University of Bristol, 2009.

24. Salmon, J., A. Timperio, V. Cleland, and A. Venn. Trends in children's physical activity and weight status in high and low socio-economic status areas of Melbourne, Victoria, 1985-2001. Aust. N. Z. J. Public Health. 29:337-342, 2005. PubMed doi:10.1111/ j.1467-842X.2005.tb00204.x

25. Shepard, R.J. Is active commuting the answer to population health? Sports Med. 38:751-758, 2008. PubMed doi:10.2165/00007256-200838090-00004

26. Sirard, J.R., and M.E. Slater. Walking and Bicycling to School: A Review. Am. J. Lifestyle Med. 2:372-396, 2008. doi:10.1177/1559827608320127

27. Sturm, R. Childhood obesity - what we can learn from existing data on societal trends, part 2. Prev. Chronic Dis. 2:A20, 2005. PubMed

28. Telama, R., and X. Yang. Decline of physical activity from youth to young adulthood in Finland. Med. Sci. Sports Exerc. 32:1617-1622, 2000. PubMed doi:10.1097/00005768200009000-00015 
29. Telford, A., J. Salmon, D. Jolley, and D. Crawford. Reliability and validity of a selfreport and proxy-report physical activity questionnaire for children: the Children's Leisure Activities Study Survey (CLASS). Pediatr. Exerc. Sci. 16:64-78, 2004.

30. Timperio, A., K. Ball, J. Salmon, et al. Personal, family, social and environmental correlates of active commuting to school. Am. J. Prev. Med. 30:45-51, 2006. PubMed doi:10.1016/j.amepre.2005.08.047

31. Verstraete, S., I. De Bourdeaudhuij, and G. Cardon. Validation of a physical activity questionnaire for children. Med. Sci. Sports Exerc. 5:S337, 2003.

32. Windle, M., J.A. Grunbaum, M. Elliott, et al. Healthy passages - A multilevel, multimethod longitudinal study of adolescent health. Am. J. Prev. Med. 27:164-172, 2004. PubMed doi:10.1016/j.amepre.2004.04.007

33. World Health Organization. Young people's health in context. Health Behavior in School-aged Children (HBSC) study: international report from 2001/2002 survey. Health Policy for Children and Adolescents no 4. Denmark: WHO, 2004. 